
методом плазменной абляции

\author{
И. Ф. Ритиня ${ }^{1,2}$, С. А. Рубинс ${ }^{1}$, А. Я. Рубинс
}

\author{
1 Латвийский университет \\ бульвар Райниса, д. 19, г. Рига, LV-1586, Латвия \\ 2 Институт красоты «Liorá» \\ ул. Таллинас, д. 18, г. Рига, LV-1001, Латвия
}

\begin{abstract}
Выбор метода удаления доброкачественных образований кожи (ДОК) в шейно-лицевой области всегда актуален. Удаление ДОК производят по медицинским и эстетическим показаниям. Предпочтителен метод с менее болезненными процедурами, коротким периодом заживления, без заметных отдаленных следов (шрамов, дисхромии) и с прогностически меньшим количеством повторных процедур.

Цель исследования. Оценка эффективности, безопасности и удобства плазменной абляции ДОК аппаратом РІехг ${ }^{\circledR}$ (GMV, Италия); сравнение скорости репаративных процессов после удаления ДОК шейно-лицевой области аппаратом Plexr ${ }^{\circledR}$ с другими аппаратными методами (по данным обзоров литературы).

Материал и методы. Нами была выделена группа пациентов, желающих удалить папилломы, ксантелазмы, дермальные невусы, дерматофибромы на лице и теле. Новообразования оценивались визуально и посредством дерматоскопа Dermlite 3DN. Пациенты с атипичными кожными образованиями исключались из исследования и направлялись на консультацию к врачу-онкологу. Каждый пациент, получив полную инсормацию о ходе процедуры и послепроцедурном уходе, письменно заверил свое информированное согласие. Плазменная абляция ДОК осуществлялась аппаратом Plexr ${ }^{\circledR}$. Повторный осмотр пациентов производился после отделения корочки с обработанного участка кожи.

Результаты исследования. Нами проведено 373 процедуры по удалению ДОК, в том числе 212 (57\%) — в шейно-лицевой области, включая 47 (13\%) случаев удаления акрохордонов, папиллом, ксантелазм, сирингом, милиумы области верхнего и нижнего века. В 98\% случаев констатировано полноценное заживление. Повторная коррекция потребовалась только одному пациенту ввиду недостаточно глубокой деструкции тканей при удалении множественных сирингом зоны нижнего века.

Заключение. Полученные результаты позволяют считать метод плазменной абляции тканей ДОК аппаратом РІехг ${ }^{\circledR}$ эфффективным, безопасным, атравматичным, экономичным, с коротким периодом заживления тканей (7-10 дней). Удаление ДОК аппаратом РІехг ${ }^{\circledR}$ - хорошая альтернатива конвенциональным хирургическим и лазерным методам, которая может быть внедрена в медицинскую практику.
\end{abstract}

Ключевые слова: дермальный невус, ксантелазма, папиллома, плазменная абляция, сирингома.

Контактная инфоормация: arubins@apollo.lv. Вестник дерматологии и венерологии 2017; (4): 44—52. 


\title{
E xperience of removing benign neoplasms of skin in cervicofacial area using the method of plasma ablation
}

\author{
I. F. Ritina ${ }^{1,2}$, S. A. Rubins ${ }^{1}$, A. Y. Rubins ${ }^{1}$ \\ ${ }^{1}$ Department of Dermatovenerology University of Latvia \\ 19 Raina Blvd, Riga, LV-1586, Latvia \\ 2 Beauty institute "Liora" \\ 18 Tallinas str., Riga, LV-1001, Latvia
}

Choosing appropriate methods for removal of benign skin lesions (BSL) in the cervicofacial area has always been an important and challenging issue. Removal of the BSL is indicated and performed for medical and aesthetic reasons. A method with less painful procedures, a short healing period, without noticeable long-lasting traces (such as scars, dyschromia) and, predictably, fewer repeat procedures is preferred.

Objectives. Evaluation of the effectiveness, safety and convenience of BSL plasma ablation using Plexr ${ }^{\circledR}$ (GMV, Italy); Comparison of the reparative processes speed after the BSL removal in the cervicofacial area applying the Plexr ${ }^{\circledR}$ device with other instrumental methods (based on literature reviews).

Materials and Methods. We identified a group of patients wishing to remove papilloma, xanthelasma, dermal nevi, dermatofibroma on their face and body. Neoplasms (skin lesions) were assessed visually and by means of the Dermlite 3DN dermatoscope. Patients with atypical skin lesions were excluded from the study and referred to a medical oncologist for consultation. Each patient, having been fully briefed on the nature and course of the medical procedure, as well as required aftercare, submitted their written informed consent. Plasma ablation of BSL was performed using Plexr ${ }^{\circledR}$ device. Re-examination of patients was carried out after the scab from the treated area of the skin had fallen off.

Results. We have performed 373 BSL removal procedures, including $212(57 \%)$ - in the cervicalfacial area, among which there have been $47(13 \%)$ cases of acrochordoni, papilloma, xanthelasma, syringoma and upper and lower eyelid milia removals. Complete healing has been recorded in $98 \%$ of all cases, with repeated corrective procedure being required only for one patient due to insufficiently deep tissues destruction in the course of multiple syringoma removal in the lower eyelid area.

Conclusion. The results obtained allow to consider the method of BSL tissues plasma ablation applying Plexr ${ }^{\circledR}$ device effective, safe, non-traumatic, inexpensive, with a short period of tissue healing (7-10 days). BSL removal with the help of Plexr ${ }^{\oplus}$ - is a good alternative to conventional surgical and laser methods, which can be introduced into medical practice.

Key words: dermal nevus, xanthelasma, papilloma, syringoma, plasma ablation. 


\section{Введение}

Доброкачественные образования кожи (ДОК) в области лица, например папилломы, дерматофибромы, ксантелазмы, сирингомы, милиумы и дермальные невусы не угрожают здоровью человека, но доставляют эстетический дискомфорт. В некоторых случаях папилломы в области шеи подвержены травматизации, что причиняет неудобство. Нередко пациенты обеспокоены возможной малигнизацией образований. Папилломы на веках могут затруднять зрительное восприятие. При обращении к специалистам с целью удалить эти образования пациенты предпочитают процедуры менее болезненные, с коротким периодом заживления, без видимых невооруженным глазом следов (шрамов, дисхромии) и с прогностически меньшим количеством повторных процедур. Специалистам приходится непрерывно искать новые безопасные и эффрективные методы лечения ДОК, комфортные как для пациентов, так и для врачей. Особенно это актуально при проведении манипуляций на труднодоступных участках кожи, в периорбитальной зоне, на свободных краях верхнего и нижнего века, на спинке и кончике носа.

Для удаления ДОК дерматологи часто прибегают к криодеструкции и электрокоагуляции ввиду их экономичности и удобства применения. Лазерная хирургия популярна и эффрективна, но она остается недоступной для широкого круга специалистов в связи с дороговизной лазерных установок. Метод плазменной абляции аппаратом Plexr $^{\circledR}$, получивший широкое распространение в странах Европы, был назван автором описываемой методики профессором Г. Фиппи (Giorgio Fippi), президентом Итальянской ассоциации косметической медицины и неаблятивной хирургии (S.I.M.E.C.N.A.), сублимацией (фризический термин сублимация обозначает переход вещества из твердого состояния в газообразное, минуя жидкое). В контексте данной статьи мы заменяем этот термин словосочетанием плазменная абляция, принятым в России для обозначения процессов плазменной деструкции тканей с помощью аппаратов «Плазмаскин» ЭКХ-12-01/ЭКХ-25-01. К сожалению, в доступных авторам медицинских источниках не удалось найти ссылки на клинические исследования по практике удаления ДОК данными аппаратами. Аппарат Plexr ${ }^{\circledR}$ (GMV, Италия) (рис. 1 и 2) относится к группе радиохирургических инструментов, применяемых также в неабляционной хирургии [1]. Действие аппарата базируется на трех фрундаментальных эффректах:

1) при активизации манипулы аппарата (см. рис. 2) возникает разница потенциалов [2] в зазоре 0,51,5 мм между наконечником манипулы $\operatorname{Plexr}^{\circledR}$ и кожей;

2) ионизируется присутствующий в зазоре между кожей и наконечником манипулы аппарата атмосферный газ, происходит образование плазмы (плазма четвертое, после твердого, жидкого и газообразно-

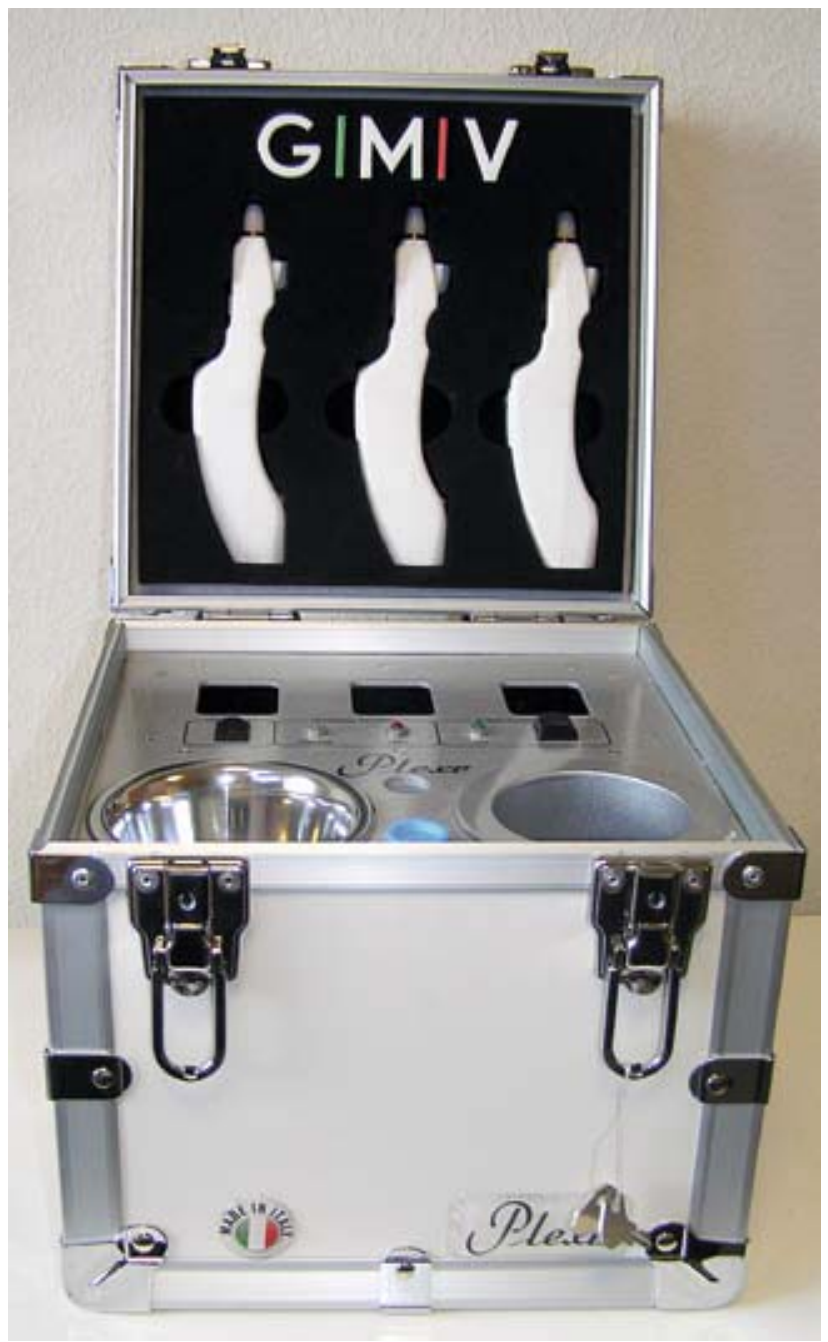

Рис. 1. Аппарат Plexr ${ }^{\circledR}$

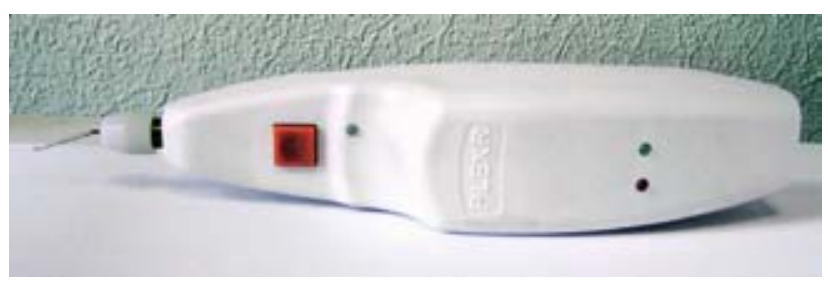

Рис. 2. Одна из трех манипул аппарата Plexr ${ }^{\circledR}$

го, агрегатное состояние вещества) и возникает эффект, подобный электрической дуге;

3) поток плазмы производит деструкцию тканей плазменную абляцию (рис. 3) [2].

Во время манипуляции происходит целенаправленное воздействие только на поверхностные ткани ДОК, 


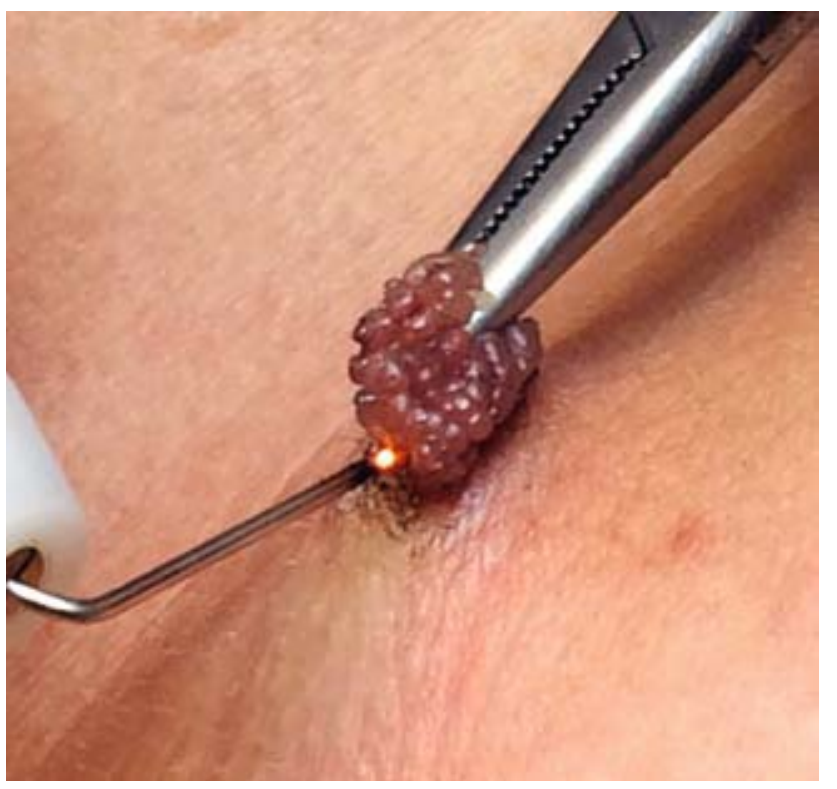

Рис. 3. Деструкция дермального папилломатозного невуса аппаратом Plexr ${ }^{\circledR}$

характеризующиеся плохой проводимостью, причем подлежащим тканям энергия не передается [2], и они подвергаются незначительной травматизации [3]. Это позволяет произвести контролируемую послойную плазменную абляцию тканей ДОК с меньшим риском таких отдаленных побочных явлений, как развитие дисхромии и появление рубцов. Именно по этой причине лечение ДОК с помощью прибора Рlexr ${ }^{\circledR}$ является эффективным и как метод представляет собой хорошую альтернативу лазерным технологиям.

\section{Цель настоящего исследования}

Проведение оценки метода плазменной абляции ДОК аппаратом Plexr ${ }^{\circledR}$ (GMV, Италия) как эфрфективного, безопасного и удобного в использовании; сравнение скорости репаративных процессов после удаления ДОК в шейно-лицевой области аппаратом Plexr $^{\circledR}$ с репаративными процессами после применения других аппаратных методов (по данным [1, 2]).

\section{Материал и методы}

Нами проведено неконтролируемое исследование, одобренное комитетом по этике Института кардиологии и регенеративной медицины клинико-сизиологических исследований, медикаментов и фармацевтической продукции при Латвийском университете (документ № 1-03/27 от 30.09.2016).

Из потока посетителей амбулаторного отделения института красоты «Liorá» была выделена группа пациентов, желающих удалить папилломы, ксантелаз- мы, дермальные невусы и дерматофибромы в области лица и тела. Каждое образование было оценено визуально, а также с использованием дерматоскопа Dermlite 3DN. Пациенты с атипичными кожными образованиями были исключены из исследования и направлены на консультацию к врачу-онкологу. Каждый пациент был полностью информирован о ходе процедуры и необходимом после нее уходе, а также заверил своей подписью информированное письменное согласие на проведение процедуры. Обезболивание производилось кремом Emla в течение 30 минут под окклюзией или с помощью микроинъекций Sol. Lidocaini hydrochloridi $2 \%$. Процедура деструкции ДОК осуществлялась аппаратом Plexr $^{\circledR}$ (см. рис. 1, 2) по методике бесконтактного точечного прерванного воздействия в сочетании с непрерывной спрейтехникой [1] (рис. 3).

У аппарата Plexr $^{\circledR}$ имеются три рабочие манипулы, каждая из которых соответствует одному (низкому, среднему или высокому) уровню мощности [1] (см. рис. 3). Уровни мощности манипул не регулируются, а для каждой манипулы определен протокол процедур. Манипула с белой меткой соответствует низкому уровню производимой энергии и предусмотрена для деструкции ксантелазм, ДОК диаметром до 2-3 см, мелких плоских бородавок и лечения угревой сыпи при активном акне [4]. Манипула с зеленой меткой соответствует среднему уровню производимой энергии и предусмотрена для деструкции ксантелазм, покрытых плотной тканью, среднего размера ДОК, коррекции шрамов постакне. Манипула с красной меткой (высокая мощность) рекомендована для деструкции фрибром, себорейного кератоза, крупных дермальных невусов и др.

В течение 3-4 дней после процедуры пациенты 2 раза в день обрабатывали раневую поверхность раствором антисептика Octenisept ${ }^{\circledR}$; им надлежало дождаться самостоятельного отслоения корочки, избегать воздействия прямых солнечных лучей, не посещать солярий в течение месяца, не заклеивать корочку пластырем, не наносить на нее никаких кремообразных средств. Повторный осмотр пациентов производился через 7-10 дней после отделения корочки с подвергнутого манипуляции участка кожи.

\section{Результаты исследования и обсуждения}

Всего нами было проведено 373 процедуры удаления ДОК (табл. 1), в том числе 212 (57\%) - в области лица и шеи, из которых 47 (13\%) были манипуляциями по удалению акрохордонов, папиллом, ксантелазм, сирингом и милий зоны верхнего и нижнего века (табл. 2).

Ряд авторов, отмечая в своих публикациях, что удаление ДОК на лице и особенно в области век и носа требует выполнения процедуры с предельной тщательностью, указывают на риск рецидивов, 
Таблица 1 Виды ДОК, удаленных аппаратом Plexr

\begin{tabular}{cccccccccc}
\hline Всего & Папилломы & $\begin{array}{c}\text { Множест- } \\
\text { венные } \\
\text { милии }\end{array}$ & $\begin{array}{c}\text { Ксанте- } \\
\text { лазмы }\end{array}$ & $\begin{array}{c}\text { Дермато- } \\
\text { фибромы }\end{array}$ & $\begin{array}{c}\text { Себо- } \\
\text { рейный } \\
\text { керато3 }\end{array}$ & $\begin{array}{c}\text { Множественные } \\
\text { периорбитальные } \\
\text { сирингомы }\end{array}$ & $\begin{array}{c}\text { Cista } \\
\text { sebaceus }\end{array}$ & Бородавки Дермальные \\
невусы & \\
\hline$n=373$ & 156 & 8 & 24 & 36 & 23 & 13 & 8 & 56 & 49 \\
\hline $100 \%$ & $42 \%$ & $2 \%$ & $6 \%$ & $10 \%$ & $6 \%$ & $4 \%$ & $2 \%$ & $15 \%$ & $13 \%$ \\
\hline
\end{tabular}

\section{Таблица 2 Локализация ДОК, удаленных аппаратом Plexr ${ }^{\circledR}$}

\begin{tabular}{lccccc}
$\begin{array}{c}\text { Всего } \\
\text { пациентов }\end{array}$ & $\begin{array}{c}\text { Лицо, } \\
\text { за исключением } \\
\text { век }\end{array}$ & Веки & Шея & Декольте & Тело \\
\hline$n=373$ & 94 & 47 & 71 & 38 & 123 \\
\hline $100 \%$ & $25 \%$ & $13 \%$ & $19 \%$ & $10 \%$ & $33 \%$ \\
\hline
\end{tabular}

образования рубцов и нарушения пигментации. В исследуемой группе в 98\% случаев было констатировано полноценное заживление без необходимости повторной коррекции. Этот факт обусловлен тем, что специалист имеет возможность прицельно точно произвести абляцию планируемого объема в пределах прилежащих здоровых тканей без их повреждения [1-3]. Повторная коррекция потребовалась только одному пациенту при удалении множественных сирингом в области нижнего века в связи с недостаточной глубиной деструкции тканей во время первой манипуляции.

Процесс удаления папиллом и ксантелазм в области век различными методами сложен из-за анатомического строения век и близости глазного яблока. J. Labandeira c соавт. [5] делится опытом лечения ксантелазм с использованием жидкого азота, отмечая простоту такой технологии и ее малую себестоимость, однако применяется этот метод редко по причине выраженного отека век. Популярно и удаление ксантелазм $\mathrm{CO}_{2}$-лазером, однако D. Satiriadis и A. Patsatsi B "European Handbook of Dermatological Treatments" [6] отмечают нарушение пигментации в 5-10\% случаев, а также высокий процент рецидивов (40\%). Рецидивы связаны с технической сложностью полного удаления тканей образования. C. Raulin c соавт. [7], удалившие 23 пациентам 52 периорбитальные ксантелазмы $\mathrm{CO}_{2}-$ лазером, выполняли каждую процедуру 4-7 проходами. Однако через 10 мес. авторы констатировали рецидив у 3 пациентов (13\%), а в нескольких случаях ими наблюдалось нарушение пигментации.

При использовании аппарата Plexr ${ }^{\circledast}$ появилась возможность безопасно удалять ткани ксантелазм, не опасаясь термической деструкции подлежащих и окружающих здоровых тканей [2, 3]. Результаты исследования свидетельствуют об эфрфективности применения аппарата $\mathrm{Plexr}^{\circledR}$ для плазменной абляции 24 ксантелазм, с учетом того, что дисхромия, выраженные шрамы и рецидивы не были констатированы по истечении 1,5 года (рис. 4). Следует отметить, однако, что процесс заживления тканей век после процедур плазменной абляции ксантелазм является более длительным по сравнению с аналогичными процессами заживления после плазменной абляции сирингом и папиллом в тех же зонах.

S. Korkmaz, F. Ekici, S. Sül [8] удаляли ДОК зоны век 75 пациентам по эстетическим показаниям, используя аргоновый лазер. Все пациенты были удовлетворены полученным эстетическим результатом. Раны эпителизировались в течение 3-4 нед., при этом у 3 пациентов была констатирована гиперпигментация.

D. Sebaratnam с соавторами [9] отмечают эффрективность удаления ксантелазм и сирингом зоны век лазерами, в то же время обращают внимание на частые рецидивы, связанные с расположением указанных образований в глубоких структурах кожи. A. Hipotaka c соавт. [10] также отмечают частые рецидивы сирингом периорбитальной зоны после их удаления $\mathrm{CO}_{2}$-лазером. Авторы объясняют это явление тем, что врач, выполняя процедуру в периорбитальной зоне, старается удалить образование с минимальной травматизацией окружающих тканей и выполняет деструкцию тканей не в полном объеме. В рамках нашего исследования было сделано по одной процедуре абляции аппаратом Plexr ${ }^{\circledR}$ множественных периорбитальных сирингом у 13 пациентов, и только в одном случае через месяц был констатирован рецидив, потребовавший выполнения повторной манипуляции. Нарушений пигментации и образования дефектов кожи не наблюдалось. S. Cho c соавт. [11] с интервалом в один месяц выполнили $\mathrm{CO}_{2}$-лазером по 2 процедуры абляции множественных периорбитальных сирингом 35 пациентам и в 14,3\% случаев констатировали гиперпигментацию.

Удалять доброкачественные образования в области носа так же сложно, как и на веках. Анатомическое строение носа, его богатое кровоснабжение и наличие хряща осложняют выполнение любой процедуры удаления доброкачественных образований [12]. 


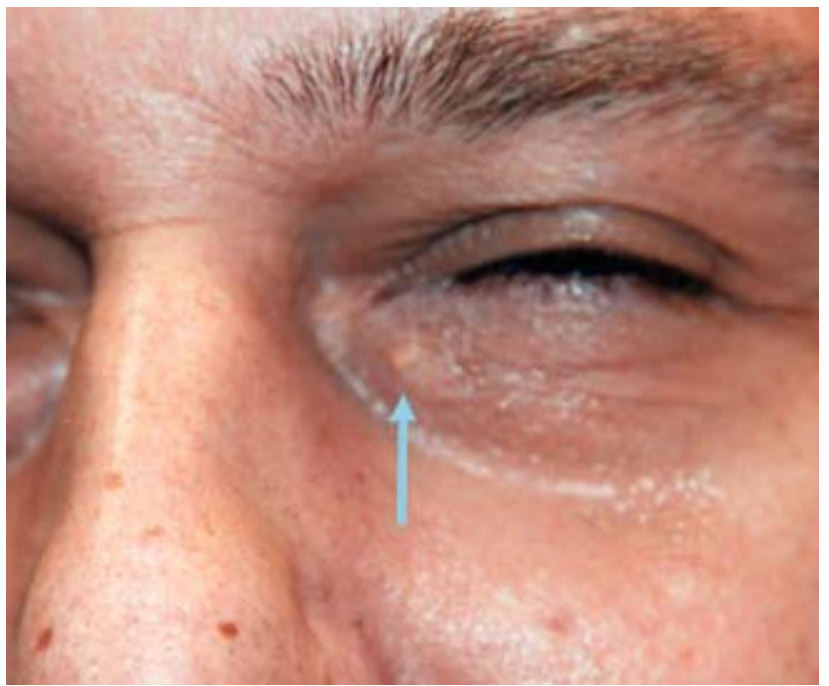

a

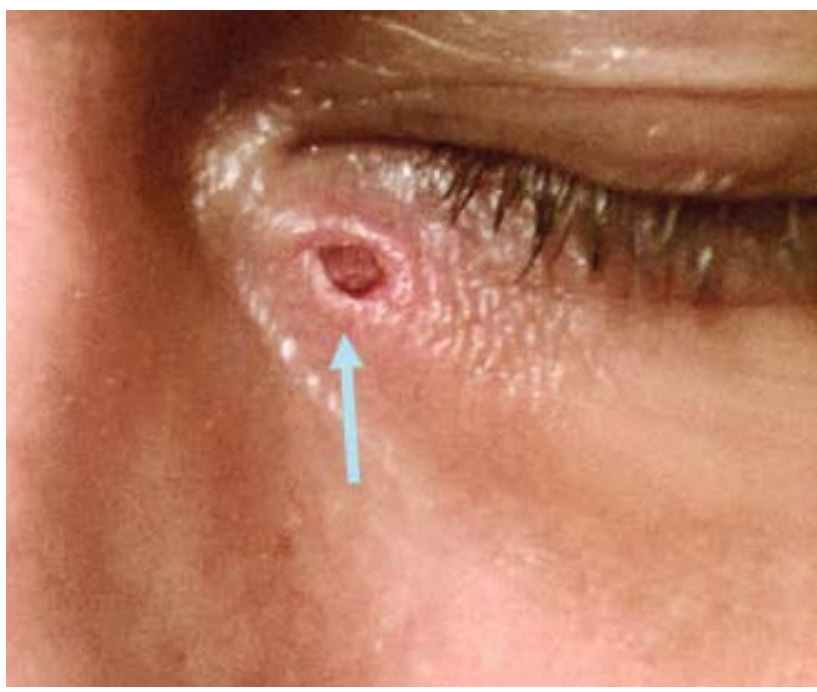

$B$

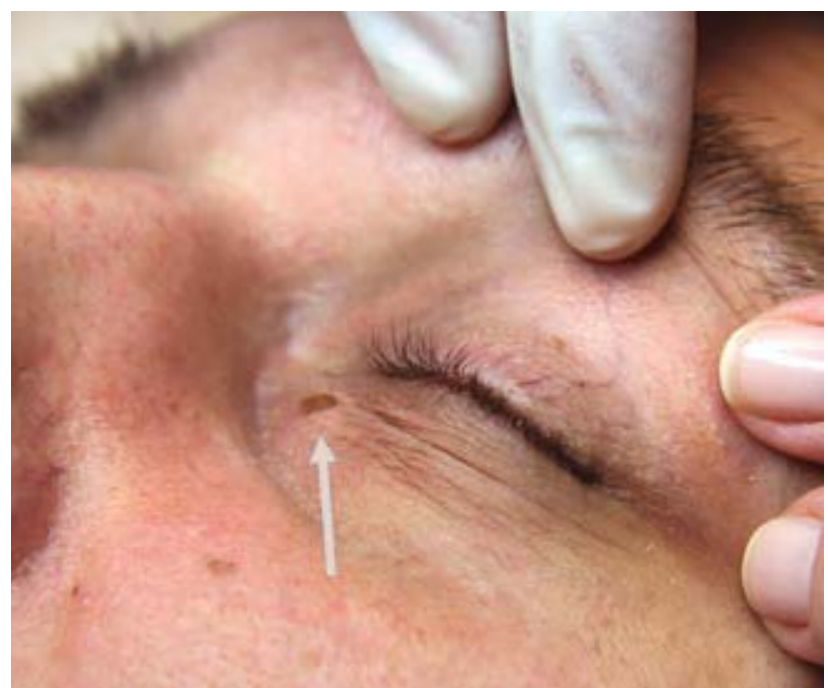

$\sigma$

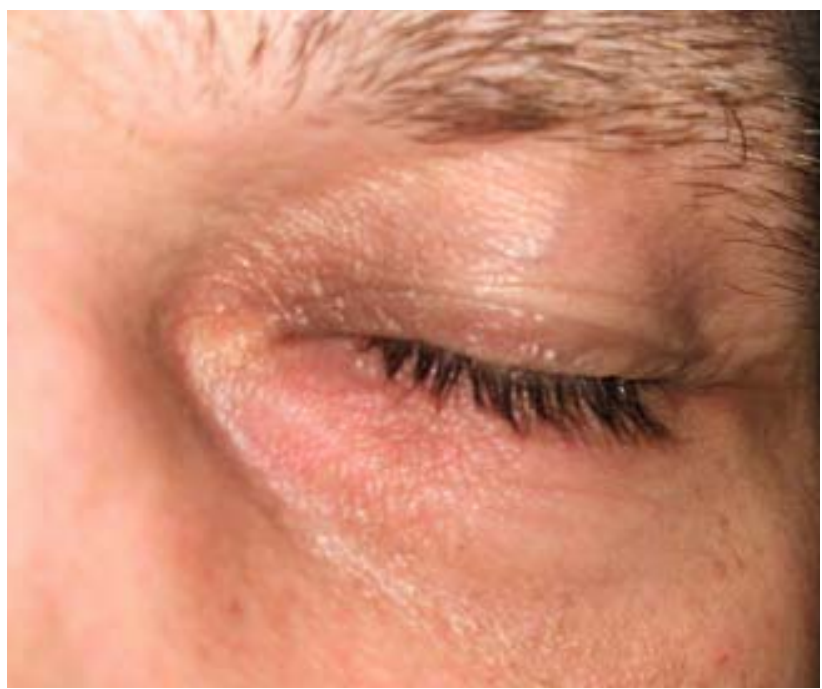

$\Gamma$

Рис. 4. Ксантелазма нижнего века: $а$ - предоперационное фрото; 6 - сразу после процедуры плазменной абляции ксантелазмы нижнего века; в — через 5 дней после процедуры плазменной абляции ксантелазмы; г - вид через 3 года и 5 месяцев после процедуры плазменной абляции ксантелазмы нижнего века

В процессе деструкции тканей важно одновременно коагулировать сосуды [13], не повреждая хрящевые структуры. S. Greenbaum и соавт. [14] отмечают, что выполняя процедуры в области носа, надо избегать высоких температур, так как помимо некроза кожи они вызывают и хондронекроз. В той же статье авторы информируют о гипопигментированных атрофических рубцах после процедур на кончике и крыльях ноca [14]. Опыт применения аппарата Plexr $^{\circledR}$ для удаления дермальных невусов на спинке, кончике и крыльях носа продемонстрировал возможность использования метода плазменной абляции в этой области без выра- женных атрофических рубцов и нарушения пигментации после процедуры (рис. 5).

В ходе исследования аппаратом $\mathrm{Plexr}^{\circledR}$ было удалено 264 папилломатозных, мягких и гиперкератозных новообразований кожи, в том числе 16 веррукозных невусов, а также 24 ксантелазмы в области век. По прошествии года после однократной процедуры выраженные рубцы и рецидивы не были констатированы ни в одном случае. Многие авторы указывают на прямую зависимость количества необходимых повторных процедур от толщины тканей новообразований. U. Hohenleutner с соавт. [15] рекомендует удалять 


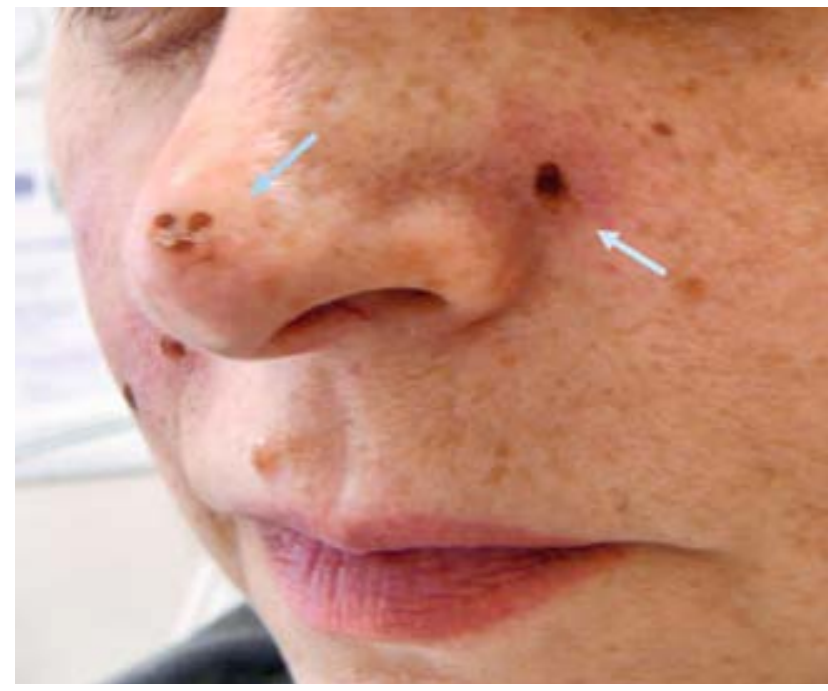

a

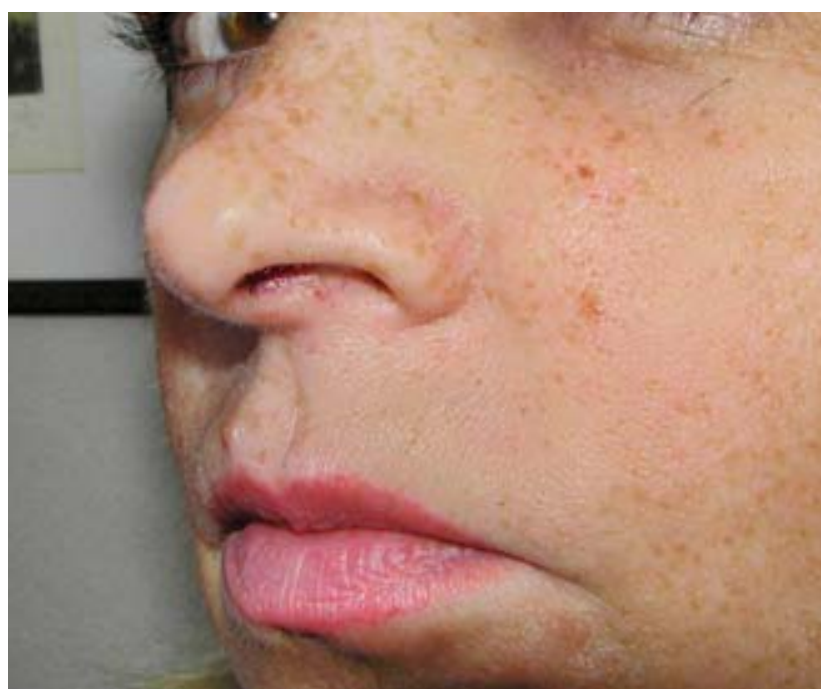

$\sigma$

Рис. 5. а - вид сразу после плазменной абляции дермальных невусов; б - вид через 9 месяцев после процедуры плазменной абляции дермальных невусов

папилломатозные и мягкие ДОК аргоновыми лазерами, а гиперкератозные образования лучше, по их мнению, подвергать деструкции $\mathrm{CO}_{2}$ лазерами. Тем не менее риск формирования рубцов довольно высок независимо от выбранного метода. S. Paradela c coавт. [16] сообщает о 25 пациентах с эпидермальными веррукозными невусами, которым было произведено по 4 процедуры удаления невусов $\mathrm{CO}_{2}$ лазером. У $33 \%$ этих пациентов были констатированы рецидивы.
J. Park с соавт. [17] использовали Er:YAG лазер для лечения 20 пациентов с эпидермальными веррукозными невусами. Авторы отметили успешность всех процедур, однако через год у 15\% пациентов были отмечены нарушения пигментации, а у 5 (25\%) пациентов развился рецидив.

В ходе нашего исследования с помощью аппарата Plexr $^{\circledR}$ было удалено 23 себорейных кератомы однократной плазменной абляцией. Во всех случаях

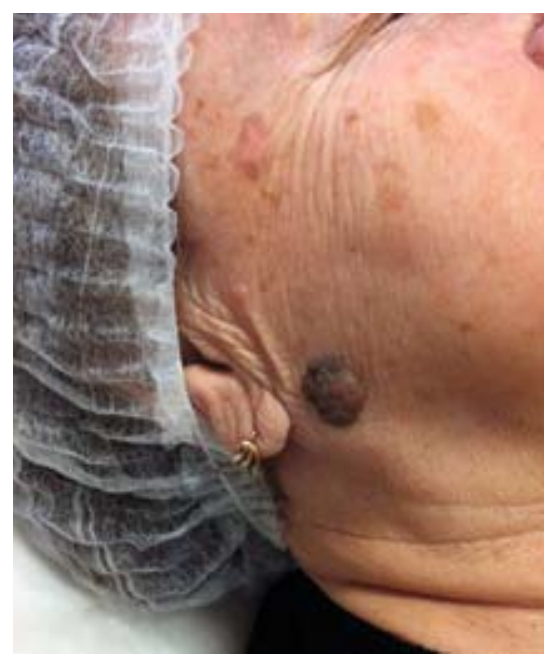

a

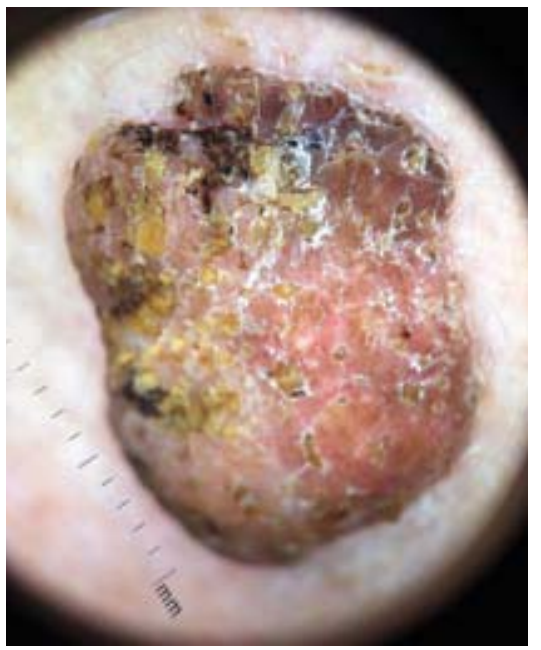

$\sigma$

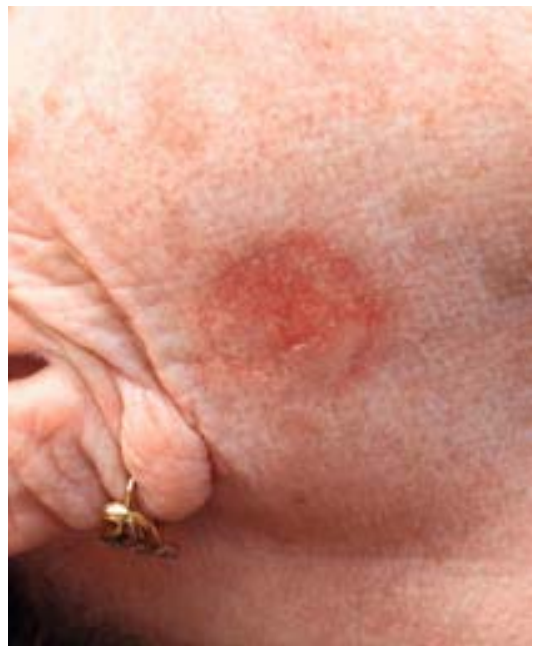

$B$

Рис. 6. а - очаг себорейного кератоза лица до процедуры удаления; б - дерматоскопия себорейного кератоза; в - на восьмой день после процедуры плазменной абляции 
заживление происходило в течение 7-9 дней (рис. 6) без последующих рецидивов. G. Culbertson [18] выполнил деструкцию 1567 себорейных кератом у 326 пациентов с применением диодного лазера $532 \mathrm{~nm}$. При этом 93\% образований удалось удалить в процессе однократной процедуры, и только в 7\% случаев манипуляцию пришлось повторить.

Абляция тканей ДОК с помощью $\mathrm{CO}_{2}$ и YAG лазеров гарантирует лучший косметический результат в сравнении с хирургической эксцизией образований, но следует отметить и вероятность рецидивов [19], атрофических рубцов [20] и локальное нарушение пигментации.

\section{Заключение}

В результате исследования было получено практическое подтверждение декларированных производителем утверждений:

1. Метод плазменной абляции аппаратом Plexr $^{\circledR}$ позволяет прицельно, слой за слоем удалить ткани ДОК, обеспечивая высокую точность и контроль процесса деструкции, в результате чего удается снизить количество рецидивов, что выгодно отличает данный метод от лазерной абляции и электрохирургической техники.
2. Наблюдение за ходом заживления с достаточной долей вероятности дает основание предположить, что процесс плазменной абляции ДОК происходит без повреждения подлежащих тканей, которые не подвергаются агрессивному термическому воздействию, и, соответственно, некроз глубоких тканей отсутствует [2]. Об этом свидетельствует значительно более быстрый (7-9 дней) процесс заживления раны после плазменной абляции по сравнению с аналогичным процессом после лазерных и электрохирургических процедур.

3. Побочные явления после процедуры плазменной абляции ДОК, такие как рубцы и нарушение пигментации, при соблюдении правил ухода за раневой поверхностью развиваются значительно реже, чем при использовании других методов удаления новообразований кожи.

Процедура плазменной абляции дОК аппаратом $\mathrm{Plexr}^{\circledR}$ относительно проста в исполнении, эффективна, атравматична для окружающих тканей, безопасна как для пациента, так и для медицинского персонала. Еще одним преимуществом метода является его относительно низкая себестоимость. Авторы полагают, что метод плазменной абляции может успешно применяться в практике дерматолога и специалиста эстетической медицины. І

\section{Литература}

1. User Manual. GMV S. R. L., Via del Buero 31, 0040, Rocca Priora RM Italy: 2011; 19, $47-58$.

2. Tsiomas G. S., Dimitris V., Nikolaos G. Clinical and Histological Presentation after Plexr application, Needle Shaping (Vibrance) and O.F.F. Pinnacle Medicine\&Medical Sciences 2015; Vol. 2 (3), ISSN:2360-9516: 522-530.

3. Scarano A.,Carinci F., Sinjari B., Artese L., Fippi G., Brunelli G., Monguzzi R. Skin lesions induced from the radiosurgical unit and voltaic arc dermoabrasion: a rabbit model. European Journal of Inflammation 2011; Vol. 9, no. 3: 89-94.

4. Geleki S., Tsioumas S., Vranou A. Plexr in Acne Treatment. Pinacle Medicine\&Medical Sciences 2015; ISSN: 2360-9516, Vol. 2 (1), Article ID pmms_171, 482—486.

5. Labandeira J., Vázguez-0sorio I., FigueroaSilva 0., Pereiro M. J., Toribio J. Tolerability and effectiveness of liquid nitrogen spray cryotherapy with very short freeze time in the treatment of xantelasma palpebrarum. Dermatologic Therapy 2015 Nov-Dec; 28 (6): 346 — 50.

6. Sotiriadis D., Patsatsi A. Xanthomas. In: Katsambas, A. D., Lotti T. M. European Handbook of Dermatological Treatments, Third Edition, Springer; 2016. p. 1063-1069.
7. Raulin C., Schoenermark M.P., Werner S., Greve B. Xanthelasma palpebrarum: Treatment with the ultrapulsed C02 laser. Lasers in Surgery and Medicine 1999; 24: 122-127.

8. Korkmaz S., Ekici F., Sül S. Argon laser-assisted treatment of benign eyelid lesions. Lasers in Medical Science 2015 Feb; 30 (2): 527-531.

9. Sebaratnam D. F., Lim A. C., Lowe P. M., Goodman G. J., Bekher P., Richards S. Lasers and laser-like devices: Part two; Australian Journal of Dermatology 2014; 55: 1—14.

10. Akita H., Takasu E., Washimi Y., Sugaya N., Nakazawa Y., Matunaga K. Case Report, Syringoma of the face with fraktional photothermolysis. Journal of Cosmetic and Laser Therapy 2009; 11: $216-219$.

11. Cho S. B., Kim H. J., Noh S., Lee S. J., Kim Y. K., Lec J. H. Treatment of siringoma using an ablative $10600 \mathrm{~nm}$ carbon dioxide fractional laser. A prospective analysis of 35 patients. Dermatologic Surgery 2011; 37: 433-438.

12. Hatem A. T., Yousef A. F., Rashad H. Dual-sided electrosurgery handpiece for simultaneous tissue cutting and coagulation: first report on a conceptual design validated by an animal experiment. Medical Devices 2015; 8: 351—357.
13. Aferzon M., Millman B. Excision of rinophyma with high-frequency electrosurgery. American Society of Dermatologic Surgery 2002; 28: 735-738.

14. Greenbaum S. S., Krull E. A., Watnick K. Comparison of $\mathrm{CO} 2$ laser and electrosurgery in the treatment of rhinophyma. Journal of the American Academy of Dermatology 1988; 18: 363.

15. Hohenleutner U., Landthaler M. Laser therapy of verrucous epidermal nevi. Clinical and Experimental Dermatology 1993; 18: 124—127.

16. Paradela S., Del Pozo J., Fernandez-Jorge B., Lozano J., Martinez-Gonzalez C., Fonseca E. Epidermal nevi treatment by carbon dioxide laser vaporization a series of 25 patients. Journal of Dermatological Treatment 2007; 18: 169_ 174.

17. Park J. H., Hwang E. S., Kim S. N., Kye Y. C. Er: YAG laser treatment of verrucous epidermal nevi. Dermatologic Surgery 2004; 30: 378-381.

18. Culbertson G. R. $532 \mathrm{~nm}$ diode laser treatment of seborrheic keratoses with color enhancement. Dermatologic Surgery 2008; 34: 525—528.

19. Hammes S. Benign Tumors and Organoid Nevi. in Raulin C., Karsai S. Laser and IPL Tehnology in Dermatology and Aesthetic Medicine Springer-Verlag Berlin Heidelberg 2011. 43-57.

20. Hruza G. J., Fitzpatrick`s J. Skin resurfacing with lasers. Clinical Dermatology 1995, 38-41. 
21. EhIman M., Bar-losef U., Paun S. D., Vashkevich M., Levit K. Radiochastotnaya terapiya v ehsteticheskoj medicine. Obzor. Plasticheskaya hirurgiya i kosmetologiya, 2011 (4): 705-721. [Элман М., Бар-Иосеф У., Паун С.Д., Вашкевич М., Левит К. Радиочастотная терапия в эстетической медицине. Обзор. Пластическая хирургия и косметология, 2011 (4): 705-721.]
22. Ponomarenko G. N., Spokojnyj L.B., Klyuchareva S. V. Vysokointensivnye lazernye tekhnologii v dermatologii; Sankt-Peterburg 2012. [Пономаренко Г.Н., Спокойный Л. Б., Ключарева С. В. Высокоинтенсивные лазерные технологии в дерматологии; Санкт-Петербург 2012.]

23. Massarweh N. N., Cosgriff N., Slakey D. P. Electrosurgery: history, principles, and current and future uses. Journal of the American College of Surgeons 2006; 202: 520—530 [PubMed].

24. Niamtu J. 3rd Radiowave surgery versus $\mathrm{CO}_{2}$ laser for upper blepharoplasty incision: with modality produces the most aesthetic incision? Dermatologic Surgery 2008; 34: 912921. [PubMed].
25. Smith T. L., Smith J. M. Radiofrequency electrosurgery. Otolaryngology-Head and Neck Surgery 2000; 11: 66-70.

26. Yates B., Que S. K., D`Souza L., Suchecki J., Finch J. J. Laser treatment of periocular skin conditions. Clinical Dermatology 2015; MarApr 33 (2): 197—206.

об авторах:

И. Ф. Ритиня — врач кафедры дерматовенерологии Медицинского фракультета Латвийского университета, директор института красоты «Liorá», Рига

С. А. Рубинс - д.м.н., доцент кафедры дерматовенерологии Медицинского факультета Латвийского университета, Рига

А. Я. Рубинс - д.м.н., профессор кафедры дерматовенерологии Медицинского факультета Латвийского университета, Рига

\section{Конфликт интересов}

Авторы заявляют об отсутствии потенциального конфликта интересов, требующего раскрытия в данной статье 